\section{Concepções sobre transtornos mentais e seu tratamento entre idosos atendidos em um serviço público de saúde mental}

\author{
Conceptions of mental disorders and their \\ treatment among elderly patients at \\ a public mental health facility
}

\author{
${ }^{1}$ Centro de Pesquisas René \\ Rachou, Fundação Oswaldo \\ Cruz, Belo Horizonte, Brasil. \\ 2 Fundação Hospitalar do \\ Estado de Minas Gerais, \\ Belo Horizonte, Brasil. \\ 3 Núcleo de Estudos \\ em Saúde Pública e \\ Envelhecimento, Fundação \\ Oswaldo Cruz/Universidade \\ Federal de Minas Gerais, \\ Belo Horizonte, Brasil. \\ ${ }^{4}$ Escola de Enfermagem \\ Universidade Federal de \\ Minas Gerais, Belo Horizonte, \\ Brasil. \\ Correspondência \\ A. S. Clemente \\ Centro de Pesquisas René \\ Rachou, Fundação \\ Oswaldo Cruz. \\ Av. Augusto de Lima 1715, \\ sala 602, Belo Horizonte, $M G$ \\ 30190-002, Brasil. \\ adautoclemente@yahoo.com.br
}

\section{Abstract}

In order to understand the thoughts and actions of elderly patients with mental disorders, we interviewed 13 elders ( $\geq 60$ years of age) treated at a public hospital in Belo Horizonte, Minas Gerais State, Brazil. Data analysis was based on the signs, meanings, and actions model. The majority of the elderly patients denied the presence of any mental disorder, but identified signs of mental distress, grouped into three main categories: "nerves", "head problems", and "craziness". All patients identified the symptom that justified their treatment and highlighted the following causes of mental disorders: family, living, physical, eating, and sleep problems, moral weakness, and aging-related frailty. Although they contended that someone else had taken the initiative to seek treatment for them, they accepted their treatment and rated it positively, despite some complaints related to their conceptions of the causes and consequences of their conditions. They mentioned medication as the main therapeutic measure, despite its adverse effects and low efficacy and the way it was prescribed by physicians.

Aged; Mental Health; Mental Disorders
Adauto Silva Clemente 1,2 Antônio Ignácio Loyola Filho 3,4 Josélia Oliveira Araújo Firmo 3

\section{Introdução}

O envelhecimento populacional é um dos fenômenos demográficos mais notórios da atualidade. Nos países desenvolvidos, a mudança na estrutura etária da população foi um processo lento, já consolidado. Nos países em desenvolvimento, esse processo iniciou-se mais tardiamente e vem ocorrendo num ritmo acelerado. No Brasil, observa-se rápido crescimento da população idosa desde a década de 60 1. A Pesquisa Nacional por Amostra de Domicílios (PNAD) de 2008 estima uma população de quase 20 milhões de brasileiros com 60 anos ou mais, correspondendo a 10,5\% da população brasileira (Instituto Brasileiro de Geografia e Estatística. http://www. ibge.gov.br, acessado em Jan/2010). Estima-se que o Brasil terá um contingente de idosos superior a 30 milhões em 20202.

Uma das consequências do envelhecimento populacional é o aumento da prevalência de enfermidades características da terceira idade. Os idosos apresentam demandas de cuidados em saúde diferentes daquelas do restante da população. Uma população mais envelhecida exige maiores investimentos de recursos em saúde e seguridade social. O Brasil defronta-se com o desafio de elaborar políticas públicas mais eficientes para oferecer melhores condições de vida e saúde à sua crescente população idosa 3 .

Dentre os problemas de saúde comuns na terceira idade, encontram-se os transtornos 
mentais, que acometem cerca de um terço da população idosa. Há poucos estudos epidemiológicos de morbidade psiquiátrica geral no idoso em nosso meio, apontando prevalências de $26,4 \%$ a $33,6 \%$ 4,5,6 em comunidades brasileiras urbanas.

O termo "transtorno mental" é utilizado nos sistemas classificatórios atuais da psiquiatria em substituição a outros termos como "doença” ou "enfermidade", visando à abordagem diagnóstica puramente descritiva (conjunto reconhecível de sintomas ou comportamentos), com a premissa de neutralidade quanto às teorias etiológicas 7.

Depressão e demência são os transtornos mentais mais frequentes na terceira idade 8 . A prevalência de transtornos depressivos em populações urbanas idosas brasileiras varia de 19,8\% até $38,5 \% 9,10$. Os quadros depressivos geriátricos têm características clínicas peculiares, o que torna o subdiagnóstico comum, exigindo abordagem diagnóstica especial 11. A demência, por sua vez, apresenta frequências de $4,2 \%$ a $7,2 \%$ nos idosos, em diversas regiões do mundo e no Brasil 12 , tendo prevalência crescente com o avançar da idade. Caracteriza-se por declínio cognitivo, progressiva dependência e incapacidade, até a necessidade indispensável de cuidadores ou de institucionalização 13. Também são transtornos mentais relevantes na terceira idade os transtornos ansiosos, o alcoolismo, os quadros maníacos, os transtornos mentais de origem orgânica, o uso abusivo e a dependência de sedativos 14,15.

Apesar disso, estudos apontam decréscimo na procura por serviços de saúde mental com o passar da idade, para os quais concorrem vários fatores, dentre eles, crenças e atitudes dos idosos frente aos transtornos mentais 16. Por outro lado, idosos com transtornos mentais apresentam maiores taxas de consultas médicas primárias e de hospitalização por diversas razões 17 , sem que o transtorno mental seja adequadamente investigado, identificado e tratado. Os idosos parecem menos capazes de perceber a presença dos transtornos mentais, e suas manifestações são interpretadas como parte inevitável do envelhecimento ${ }^{18}$. Tudo isso leva a presumir uma situação de desassistência, possivelmente agravada pela escassez de políticas de saúde e de formação profissional voltadas para a atenção à saúde mental do idoso ${ }^{3}$.

Quando se pretende melhorar a atenção em saúde, é importante avaliar e programar intervenções educativas ou terapêuticas, levando-se em consideração as percepções dos próprios pacientes 19. Para planejar e aprimorar a assistência à saúde mental do idoso é importante considerar as concepções desses pacientes sobre os transtornos mentais e seu tratamento. Na literatura con- sultada, não encontramos estudos que tenham investigado as concepções de idosos portadores de transtorno mental sobre o seu quadro. Neste estudo, qualitativo, a abordagem antropológica foi empregada para investigar o universo de representações (maneiras de pensar) e comportamentos (maneiras de agir) dos pacientes idosos diante dos transtornos mentais.

\section{Metodologia}

\section{Quadro teórico}

Sob o ponto de vista da Antropologia Médica, a experiência da doença não é um simples reflexo de um processo patológico no sentido biomédico do termo, sendo concebida como uma construção cultural. A influência do universo social e cultural sobre as concepções e comportamentos vem sendo cada vez mais valorizada nas intervenções preventivas e terapêuticas na área da saúde, rompendo com a tradição que privilegiava aquelas referentes ao modelo biomédico 20 .

Geertz 21 concebe a cultura como um universo de símbolos e significados que permite a um grupo interpretar sua experiência e guiar suas ações. Essa perspectiva interpretativa da cultura teve vários desdobramentos no campo da abordagem de saúde e doença. Um deles é a diferenciação paradigmática entre "doença processo" e "doença experiência” estabelecida por Eisenberg 22. A “doença processo" (disease) se refere às anormalidades dos processos biológicos e psicológicos, na função e/ou estrutura dos órgãos e sistemas do corpo, e a "doença experiência” (illness) à experiência subjetiva de mal-estar. Kleinman 23 desenvolveu o conceito de "modelos explicativos" (explanatory models) para descrever o conjunto de crenças e expectativas sobre uma doença, formuladas por indivíduos em uma determinada cultura. Esses modelos ordenam e dão significado à experiência de determinada doença, com relação a suas causas, sintomatologia, curso e tratamento apropriado.

De acordo com essa perspectiva, o modelo biomédico das doenças também é sustentado por determinantes culturais e todas as interpretações das doenças são socialmente construídas, qualquer que seja a posição teórica ou ideológica. Diferentes categorias de pessoas empregam modelos explicativos diferentes, fato que pode gerar problemas na comunicação entre profissionais e pacientes 24 . Conhecer as diferenças pode facilitar a comunicação entre tais grupos, aumentando a compreensão e a aderência a intervenções e tratamentos preconizados, condi- 
ções essenciais para o sucesso de qualquer programa de saúde.

Assim, entende-se que os comportamentos de uma população frente a seus problemas de saúde, incluindo a utilização dos serviços de saúde, são construídos mediante universos de significados socioculturais. Os serviços de saúde constituem um lócus privilegiado de estudos para se compreender o que representa a doença ou o tratamento 25 .

\section{Local do estudo}

A pesquisa foi realizada no Hospital Galba Velloso (HGV), em Belo Horizonte, Minas Gerais, Brasil, hospital psiquiátrico público, pertencente à Fundação Hospitalar do Estado de Minas Gerais (FHEMIG). O HGV atende clientela de 18 anos de idade ou mais, procedente da capital, da região metropolitana e de outras cidades de Minas Gerais.

Em consonância com a Reforma Psiquiátrica Brasileira 26, houve no HGV progressiva redução do número de leitos de internação de média permanência e ampliação do serviço de atendimento a urgências, que passou a denominar-se Centro de Acolhimento a Crises em 2001. O Centro de Acolhimento a Crises constitui a porta de entrada do HGV e oferece leitos de curta permanência para transtornos mentais agudos, até sua estabilização, possibilitando pronto retorno do paciente a seu meio de origem, para continuidade do tratamento nos serviços de saúde mental de referência 27 . Segundo o Serviço de Gestão de Informação do HGV, no ano de 2008, foram realizados 9.147 atendimentos no Centro de Acolhimento a Crises. Destes atendimentos, $562(6,14 \%)$ foram feitos a pacientes com 60 anos ou mais.

\section{População de estudo}

Foram elegíveis para o estudo todos os idosos atendidos no HGV entre março e maio de 2009, que permaneceram no hospital por mais de 24 horas, que tinham condições de entender sua participação no estudo e com habilidade para comunicar-se, ou seja, livres de déficits cognitivos e sensoriais significativos. As entrevistas foram realizadas em momento próximo à alta hospitalar, quando o paciente estava com o transtorno mental estabilizado. O fechamento amostral foi determinado pelo critério de saturação 28 .

\section{Coleta de dados}

Foram realizadas entrevistas abertas, com roteiro semiestruturado, buscando elucidar as concepções sobre os transtornos mentais, suas manifestações, atitudes diante do problema, alternativas de tratamento, possibilidades de cura, motivo(s) que levaram à busca do hospital e expectativas e percepções sobre o tratamento recebido. Questionou-se, a princípio, qual o motivo da internação e como o idoso avaliava a própria saúde, evitando-se mencionar qualquer termo equivalente a transtorno mental. Caso ele utilizasse algum termo equivalente, esse continuava sendo utilizado pelo entrevistador. Caso o entrevistado não utilizasse espontaneamente qualquer termo equivalente, foi diretamente questionada a presença de algum problema mental (termo identificado em uma análise de campo semântico, equivalente ao termo médico transtorno mental).

\section{Análise dos dados}

$\mathrm{Na}$ análise dos dados, foi utilizado o modelo de análise dos signos, significados e ações, que objetiva uma articulação entre ações individuais, códigos culturais, contexto macrossocial e determinação histórica ${ }^{29}$. Tal modelo propõe uma inversão da direção habitual dos estudos sobre representações de saúde/doença. A análise parte do nível pragmático para esclarecer o nível semântico, promovendo um diálogo entre a particularidade dos comportamentos em relação à saúde e a generalidade do modelo biomédico, elucidando as lógicas culturais subjacentes 20 . O modelo busca conhecer as maneiras de pensar e agir de populações, identificando categorias usadas por diferentes subgrupos de pessoas para reconhecer, explicar e reagir aos problemas de saúde, construindo um sistema de signos (de adoecimento), de significados (atribuídos à experiência da doença) e práticas (de cuidado). Permite acessar lógicas conceituais privilegiadas por uma população na compreensão de determinado problema de saúde, assim como identificar elementos que intervêm na construção de comportamentos adotados por essa população diante do problema 20 .

As entrevistas foram gravadas e transcritas. Após leituras atentas das mesmas, foram identificadas unidades significativas e criadas categorias analíticas. A codificação foi testada nas entrevistas e revisada para que todas as informações obtidas pudessem ser agrupadas fundamentandose nessas categorias, com um mínimo possível de ambiguidade. Em seguida, foram identificadas as ocorrências de cada categoria analítica e feita extração de textos que correspondiam a uma ou mais categorias de informação para a análise de conteúdo. Fundamentando-se nesse material, buscou-se a interação entre as distintas catego- 
rias. Assim, foram identificadas as práticas associadas ao transtorno mental e categorizados os signos e as interpretações sobre tais problemas e as concepções sobre tratamentos recebidos e/ou que deveriam ser idealmente realizados.

\section{Aspectos éticos}

Todos os participantes assinaram um termo de consentimento, em acordo com a Resolução $n^{\circ}$. 199/1996. A pesquisa foi aprovada pelos Comitês de Ética do Centro de Pesquisas René Rachou e da FHEMIG.

\section{Resultados}

Foram entrevistados 13 pacientes, sendo oito do sexo masculino (M) e cinco do sexo feminino (F), com idades variando de 60-83 anos. Desses, oito eram procedentes de Belo Horizonte ou Região Metropolitana e os outros cinco do interior do estado (M1, F4, F6, M11, F12). Seis estavam casados, três separados (M1, F5, M9) e os outros quatro eram viúvos (F6, M7, F12, F13). Quase todos tinham escolaridade equivalente ao ensino fundamental incompleto, um era analfabeto (M3) e um tinha escolaridade superior (M9). Dos 13 entrevistados, nove tiveram a primeira passagem pelo HGV no ano de 2009 e dois negavam consultas psiquiátricas prévias. Somente dois estavam em enfermarias de média permanência; os demais foram entrevistados no Centro de Acolhimento a Crises. Os diagnósticos psiquiátricos principais foram: transtornos psicóticos (M1, M2, F4, F5, M9, M10, F12), transtornos de humor (M3, F6, M11, F13) e demência (M3, M7, M8). Na análise das entrevistas, não foram identificadas diferenças entre as concepções apresentadas pelos idosos de acordo com idade, situação conjugal, escolaridade e de acordo com o diagnóstico psiquiátrico e o tempo de internação.

Todos os entrevistados sabiam que estavam internados em um hospital psiquiátrico. Apesar disso, a maioria deles afirmou gozar de boa saúde, negando a presença de qualquer problema mental. Somente dois dos entrevistados reconheciam a pertinência da internação psiquiátrica. Os demais consideravam a permanência hospitalar desnecessária. Todos manifestaram a preferência pelo tratamento no próprio ambiente de origem, especialmente pela possibilidade de estar ao lado de familiares: "no hospital dá os remédios nas horas. Mas se a gente pudesse tratar em casa, eu achava melhor. Mesmo achando o hospital bom, eu quero ir embora" (M11).

\section{$\underline{\text { Signos }}$}

A maioria dos entrevistados negou a presença de transtorno mental, entretanto, todos referiram ao menos um signo que justificaria alguma intervenção, em razão do sofrimento, perturbação ou interferência em suas atividades diárias. Quando questionados sobre como identificar um portador de transtorno/problema mental, foram evocados outros signos.

Os signos autorreferidos foram bastante variados, sendo possível agrupá-los por algumas semelhanças e pela frequência das citações. Os mais comuns foram alterações do sono (ficar acordado, não dormir, dificuldade para dormir ou insônia). Para dois entrevistados, este era o único problema existente: "eu só tive insônia, né? Insônia não é problema mental” (M9).

Seguem-se os relatos de sensações referidas na região da cabeça, como cabeça ruim/fracal leveltonta ou mente ruim/confusa. Houve uma analogia desses signos com outros, como ficar fora de si, esquecimentos ou memória ruim.

Destacaram-se ainda signos de caráter físico, referidos no corpo, como fraqueza, corpo fraco/ ruim, nervosismo/nervoso, dores, câimbras, malestar, tremura, zonzeira. Evocaram-se também as perturbações nas funções fisiológicas, especialmente as ligadas às funções de nutrição/digestão/excreção (não comer, não se alimentar, enjôo, boca seca, intestino preso) e as alterações psicomotoras, tanto de lentificação - expressa em termos como lerdeza e lentidão - quanto de sua exacerbação, com sensação de desinquietude ou falta de sossego.

Descreveram-se também signos de caráter mais subjetivo, como falta de alegria, tristeza e solidão, choro, e outras descrições peculiares do sofrimento, como arrocho no peito, sentir-se assustado, sem liberdade, ter uma faca no coração.

Quanto aos signos associados aos transtornos mentais, a agressividade foi citada pela maioria, por meio de expressões como ser agressivo, bater, jogar, quebrar, machucar, matar. Também foram referidas perturbações da linguagem, ressaltando-se o aspecto incoerente ou desorganizado do discurso. Outras características reportadas são dificuldades de raciocinar, pensar ou tomar decisões, confusão ou incapacidade de concluir o que se começa.

As alterações do sono e da alimentação foram evocadas, às vezes num contexto de recusa $\mathrm{e}$ teimosia. Outras experiências foram citadas uma única vez, como escutar vozes, enxergar o que não deve, perturbar pessoas, usar vestes inadequadas, andar de um lado para o outro, ficar rindo, mexer nas coisas dos outros. 


\section{Significados}

Os signos referidos pelos entrevistados tiveram estreita relação com os fatores causais atribuídos ao seu sofrimento, em que predominaram situações vivenciais, como frustrações e perdas: "acho que é a vida (...). As dores que a gente passa. As dores de tristezas" (F6).

Dentre tais vivências, questões familiares encontram destaque. Evocaram-se as experiências de abandono, rejeição e solidão; relações conflituosas, particularmente com os filhos e com o cônjuge (entre as mulheres): "não foi problema de doidura.Foi problema como meu maridolá” (F13).

Outros fatores foram apontados, destacandose as lesões físicas na cabeça ("Não era pra eu ter a cabeça boa; porque eu já apanhei tanto na cabeça" [F5]) e o próprio processo do envelhecimento ("A gente que passou de certa idade, (...) vai aparecendo umas macacoa, né?” [M7]). A falta de sono e a alimentação inadequada poderiam causar certo enfraquecimento, tornando a pessoa mais vulnerável a esse tipo de adoecimento: "Não se alimentar direito é perigoso ficar com os nervos fracos também" (F5).

A contextualização dos signos e significados descritos permitiu a delimitação de três categorias de transtornos: nervoso, problema de cabeça e doidura.

A categoria nervoso inclui o que também se nomeia como nervosismo, depressão ou problema na alma. Manifesta-se com tristeza, irritabilidade, inquietude e signos de expressão mais corpórea. É determinada por situações mais cotidianas de perdas e conflitos: "Troquei um gado a troco de um tanque. O tanque era ruim, (...) estragou e eu fiquei assim nervoso... Sinto assim, uma ruindade no corpo, na cabeça, uma tremendade... Fico acordado, desinquieto; não tem nada que sossega eu" (M11).

A segunda categoria-problema de cabeça-é descrita com termos que sugerem uma localização ou uma origem (cabeça, mente ou cérebro), e seria determinada por fraqueza, debilidade ou lesão. Podemos dividi-la em duas subcategorias, de acordo com a duração e o tipo de dano. Uma delas de caráter temporário, determinada por um evento de ação imediata (aborto, "panca$d a$ ”, perda inesperada, emoção muito intensa), causando um desequilíbrio físico ou emocional agudo e intenso, cuja principal manifestação é a perda temporária do juízo, evidente na seguinte fala: "Meu marido bateu em mim e eu fiquei com a cabeça meia fraca (...) Fora de si” (F5). A outra subcategoria é descrita como uma espécie de enfraquecimento das funções mentais de instalação lenta, determinada por situações de longo prazo ou pelo próprio envelhecimento, manifes- ta por esquecimentos, sensação de cabeça aérea ou lerdeza: "Sou lerdo; esqueço as coisas rápido demais. É a idade que faz isso com a gente... [a cabeça] fica leve" (M8).

A outra categoria apreendida é a doidura, cujo portador é identificado pelo termo doido. Sua descrição mostra-se mais uniforme e delimitada que as categorias expostas acima. Os entrevistados recusam tal condição para eles próprios e vinculam-na aos sentimentos ruins, à má educação ou à incapacidade de conter as tendências nocivas. Suas manifestações incluem comportamentos que denotam maldade ou intenso descontrole. Alguns atribuem esse problema ao afastamento ou desafio à autoridade divina, algo do que se deve evitar até mesmo falar ou pensar, como observamos neste relato: "Aí eu nunca toquei nesse tipo de tema não, não tenho esse tipo de coisa não" (...) "É por causa de inveja, por causa de orgulho... A inveja puxa o problema. Faz desordem contra saúde do outro. Trata mal" (M1).

As perturbações alimentares e do sono se destacam como signos de qualquer dessas categorias acima. São consideradas não apenas manifestações, mas também possíveis causadoras de tais problemas.

A evolução de tais quadros dependeria de suas causas e da possibilidade de tratamento. Há desde os que acreditam ("Às vezes até cura" [M11]), até os que não acreditam na cura ("Não tem homem que cura isso" [M3]), passando pela possibilidade de melhora dos sintomas. Os quadros cujos fatores causais são temporários seriam também transitórios.

\section{$\underline{\text { Ações }}$}

O uso de medicamentos é a medida privilegiada pela maioria para tratar de seus problemas. Aos mesmos é atribuída a capacidade de controlar e acalmar, fornecer disposição e força: “Nunca esquecendo de tomar aqueles remédios básicos para se manter, né? (...) Acalma, né?” (M9).

Entretanto, quando avaliamos os relatos em profundidade, revelam-se atitudes ambivalentes com relação aos medicamentos: dúvidas quanto à eficácia, desconfiança quanto ao modo como são preconizados pelos profissionais de saúde, sugerindo que seu uso deveria ser restrito à necessidade percebida pelos próprios pacientes. Alguns manifestam explicitamente a resistência ao tratamento, por causa dos efeitos adversos dos medicamentos e temores quanto à sua capacidade de provocar problemas. O uso é mantido sob outras influências, como para satisfazer a familiares ou às normas institucionais. $\mathrm{O}$ que foi relatado acima está evidente nos dois excertos a seguir: 
"Estou tomando o remédio porque, internou aqui, é pra tomar remédio; tem que respeitar (...) mas se eu não precisar, ta tudo bem... Tomo remédio assim: se eu precisar" (M2).

"Desde que eu comecei, eu nunca parei... Agora, eles falam que eu não tomo. Eu tomo... Se eu parar, é só um dia ou dois. Sabendo tomar, eles não é ruim não" (F5).

A internação psiquiátrica é considerada um recurso de tratamento para indivíduos com signos da "doidura". Verificamos duas posturas predominantes com relação aos motivos da própria internação: discordância e desconhecimento. A maioria discorda da indicação de internação, cuja decisão partiu de outros, sob influência de sentimentos e interesses de conotação negativa: " minha menina até hoje me interna; me internou de falsidade, que passou para o lado do pai dela" (F5). Outros referiam desconhecer os motivos que levaram ao atendimento; alguns, inclusive, ignoravam como se deu sua condução até o hospital: "quando eu dei por si, já estava aqui" (M8). Apesar disso, todos aceitavam a permanência hospitalar e as condutas da equipe profissional, inclusive elogiando o tratamento recebido e reconhecendo seu benefício.

Foi frequente a descrição de conflitos precedendo a internação e o relato do alívio obtido com o afastamento de tais situações. Outros elementos encontrados no hospital tiveram seus efeitos positivos ressaltados, dentre os quais o sono, a boa alimentação, o descanso, a regularidade de horários na administração dos medicamentos e alimentos: "eu ter o remédio a tempo e à hora; eu ter meu banho a tempo e à hora" (F6). A postura cuidadosa, compreensiva, e até educativa dos familiares e dos profissionais de saúde é considerada um fator facilitador da melhora: "quando eu estou ruim mesmo, eles me acodem e me cuidam... Tratamento é ver a necessidade da gente" (F6).

A importância de outras intervenções também foi apontada, como atividades ocupacionais e consultas com psicólogos. Outras medidas, que desvelam crenças sobre a determinação moralreligiosa dos transtornos mentais, são indicadas para lidar com tais problemas: o trabalho, a reflexão, preparados de ervas (beberagem); intervenções espirituais e religiosas, como feitiços, orações e pegar-se com Deus.

\section{Discussão}

As categorias reconhecidas pelos entrevistados em sua experiência de sofrimento são nervoso, problema de cabeça e doidura, que representam modelos culturais de doença, ou modelos explicativos, como concebidos por Kleinman 23.
Observou-se uma diferenciação entre essas três categorias, que remetem à própria experiência (illness), e aquela que é fornecida pelo modelo biomédico: o transtorno mental (disease). Houve tendência a desconsiderar a categorização biomédica, flagrante na denegação da presença de transtornos mentais e dos diagnósticos fornecidos por profissionais de saúde.

Pesquisas anteriores que enfocaram a experiência do adoecer psíquico apontaram alguns resultados semelhantes. Duarte 30 enfatizou a linguagem do nervoso em sua relação com a cultura das classes trabalhadoras urbanas, como um código específico para falar de embaraços da vida prática, do embate entre valores e situações do cotidiano. Segundo esse autor, na concepção popular, nervo é uma entidade difusa por todo o corpo, ainda que tenha uma associação mais estreita com a cabeça. O nervoso comportaria duas possibilidades: estar nervoso - estado de perturbação mais leve ou mais passageiro atribuível prioritariamente a uma causalidade externa; e ser nervoso - estado mais intenso e permanente em que a ênfase não recai nos fatores externos, mas no modo e qualidade interior da perturbação. Em nosso estudo, não encontramos essa última descrição, sendo o "nervoso" entendido como um estado, mais que um modo de ser. Outros autores obtiveram descrições e interpretações semelhantes para a categoria nervoso 31,32 . Todos constataram a tendência a descrever o sofrimento em termos corporais e sua relação com experiências e eventos de vida. Tais autores consideram que essas pessoas vivenciam o sofrimento de forma integrada, ao contrário do que veiculam os modelos profissionais, que tendem a delimitar o plano somático separado do plano psíquico.

Tsu \& Tofolo 33 estudaram as concepções etiológicas de pacientes psiquiátricas internadas em um hospital psiquiátrico e encontraram o predomínio de explicações psicossociais para o transtorno mental, que estaria intimamente ligado às emoções e aos sentimentos. Para esses autores, isso poderia representar uma maneira de tornar o problema pessoal mais leve e suportável, admitindo possibilidades de recuperação.

A categoria problema de cabeça foi identificada por Villares et al. 34 na investigação de concepções da doença em familiares de pacientes com diagnóstico de esquizofrenia. A descrição foi semelhante à que encontramos entre os participantes deste estudo, que circunscrevem um processo disfuncional, localizado em uma parte ou órgão do corpo, desencadeado por múltiplos fatores e que denotam determinação orgânica de tais problemas. Segundo tais autores, poderíamos constatar aqui uma apropriação de concepções médicas, traduzidas pelos pacientes em 
termos de sua própria visão da realidade clínica. Algumas diferenças relevantes foram encontradas em nosso estudo, no qual não houve nenhuma referência à hereditariedade na causalidade dos mesmos. Outra diferença é a descrição de um modo de enfraquecimento mais agudo e intenso das funções mentais, de caráter traumático, cuja relevância é minimizada por tratar-se de um estado temporário.

Nesta pesquisa, a idade avançada foi apontada como um fator causal para os problemas de cabeça, em decorrência de um processo natural, próprio do envelhecimento. Carvalhais 35 encontrou resultado semelhante entre idosas da comunidade portadoras de quadros depressivos. Porém, naquele grupo, a idade foi um fator naturalmente associado com tristeza e desânimo, ou um fator que diminuiria a resistência frente aos problemas. O grupo pesquisado neste estudo ressaltou o aspecto da perda funcional associada ao envelhecimento. Tudo isso pode levar a considerar a procura do tratamento desnecessária ou ineficaz.

Quanto aos transtornos mentais, vimos que são reconhecidos como categoria pertencente ao discurso biomédico. Sua descrição e explicação tiveram uma estreita e curiosa coincidência com a categoria doidura. Embora entendidas como entidades separadas, transtorno mental e doidura compartilham várias características. Quase todos os entrevistados negaram sua presença, e foi frequente a atribuição de ambas a questões de ordem moral. Ambas são identificadas por alterações mais perturbadoras do comportamento, da percepção e do pensamento, nos quais fica evidente a importância atribuída àquilo que compromete a capacidade de convivência e interação social e a autonomia. Podemos considerar a categoria doidura análoga à concepção popular de loucura. A relação entre loucura e valores morais já foi amplamente descrita na literatura 36 . Nesta pesquisa foi encontrada também a relação entre valores culturais e a noção médica de transtorno mental, já apontada em outro estudo brasileiro 37 .

Alguns estudos 33,34 verificaram a atribuição explícita de tais quadros a interferências espirituais. Não seria surpresa observar o mesmo no presente estudo, devido à penetração de ideias religioso-espiritualistas em nosso meio. Entretanto, isso não foi observado, o que poderia ser explicado pelo contexto em que se realizaram as entrevistas; no caso, um serviço de saúde. Suspeita-se que as atitudes dos pacientes podem variar de acordo com o contexto ou a orientação institucional de onde se encontram. Inicialmente eles hesitariam em revelar suas crenças aos profissionais de saúde, mas elas apareceriam implicitamente em suas falas ${ }^{38}$. Não foram incomuns as evocações religiosas e referências sutis à religiosidade em meio às frases dos entrevistados desta pesquisa, o que sugere que suas crenças e tradições religiosas ajudem a explicar e a enfrentar o sofrimento experimentado por eles.

A maioria dos participantes avaliou positivamente a própria saúde e negou a presença de transtornos mentais. Contudo, a internação e o tratamento médico foram bem aceitos e valorizados como alternativa legítima e eficaz para lidar com os sintomas e problemas por eles enfrentados. Isso, de alguma maneira, pode representar o reconhecimento da presença de algum sofrimento psíquico. Mas a responsabilidade sobre a decisão da internação foi transferida para aqueles que conduziram o paciente ao hospital, ou seja, foram eles que reconheceram os signos e os interpretaram de maneira a considerar necessária a ação de buscar o atendimento psiquiátrico de urgência.

A negação do transtorno mental é classicamente atribuída na psiquiatria à falta de insight (ou de consciência de morbidade), como manifestação da própria patologia de base, sendo uma condição comum nos quadros psicóticos e em outros transtornos mentais graves 39 . Kirmayer \& Corin 40 apontam que fatores de ordem cultural participam da construção social e cognitiva da percepção de si e do reconhecimento da presença de transtornos mentais. David (1990, apud Kirmayer \& Corin 40 ) apontou para a existência de três dimensões do uso do termo insight na clínica: (1) o reconhecimento da presença do transtorno mental; (2) a habilidade em reconhecer o caráter patológico de suas manifestações; (3) a aderência ao tratamento. Assim, mesmo negando a presença do transtorno, os pacientes podem ser aderentes ao tratamento, e grande parte deles é capaz de identificar comportamentos e idéias associados aos transtornos mentais.

Uma das explicações possíveis para a negação do "transtorno mental" pelos pacientes seria uma tentativa de proteger-se do estigma social. Assim como o significado dos sintomas, o estigma a eles associado também tem sido estudado como um processo cultural, social e interpretativo, e imbuído de noções morais ${ }^{41}$. Goffman 42 descreveu uma série de estratégias que sujeitos utilizam para minimizar o estigma. Uma delas é a manipulação da informação, como o "encobrimento", que pudemos constatar neste estudo, na tentativa de "imprimir um caráter mais benigno à própria condição, apresentando os signos de seu estigma como signos de outro atributo que seja um estigma menos significativo" 42 (p. 106). O mesmo autor cita também a assimilação do estigma pelo indivíduo estigmatizado, que compartilha 
crenças sobre sua identidade com a sociedade em geral, o que observamos aqui na repetição, pelos próprios entrevistados, de alguns dos mais freqüentes conceitos estigmatizantes associados aos transtornos mentais: a violência e a fraqueza moral 43,44. Existiria uma recusa em reconhecerse como indivíduo portador de características que eles próprios rejeitam.

A afirmação da própria autonomia seria um aspecto implícito na negação da existência de transtornos mentais, já que os indivíduos dependentes são considerados um problema social nas comunidades industriais e urbanas, característica que aproxima a velhice e a loucura de outras formas de marginalização. Outra explicação possível é que tal denegação seja uma estratégia para lidar com uma realidade carregada de sofrimento e dificuldades, mantendo afastadas experiências dolorosas e incompreensíveis, e sustentar expectativas de melhora ou cura.

\section{Considerações finais}

Este estudo mostrou as concepções sobre transtornos mentais e seu tratamento dos idosos atendidos no HGV. A maioria deles não reconhece a presença do transtorno, mas identifica signos de sofrimento, que articulam em três categorias: nervoso, problema de cabeça e doidura. $\mathrm{O}$ tratamento tem seu valor reconhecido, mas com certas ressalvas que estão articuladas com seus próprios conceitos sobre causas e consequências de tais perturbações.

Estes resultados podem contribuir para facilitar a abordagem dos idosos portadores de transtornos mentais. Conhecendo as concepções dos mesmos, os profissionais poderão articulálas com as concepções fornecidas pela literatura científica, facilitando a comunicação entre profissional e paciente e melhorando a qualidade do atendimento.

Outra possível contribuição deste trabalho é melhorar o entendimento de realidades presentes na abordagem dos transtornos mentais dos idosos, como: fatores que determinam a diminuição da procura por tratamento, dificuldades no reconhecimento e manejo desses transtornos pelos profissionais de saúde e na aderência dos pacientes ao tratamento.

Os resultados deste e de outros trabalhos poderão contribuir no planejamento e organização de programas de atenção à saúde mental dos idosos e ajudar a prevenir ou minimizar o impacto dos transtornos mentais sobre a qualidade de vida desses pacientes.

\section{Resumo}

Para compreender os modos de pensar e agir de pacientes idosos diante dos transtornos mentais, foram entrevistados 13 idosos ( $\geq 60$ anos), atendidos em hospital público de Belo Horizonte, Minas Gerais, Brasil. A análise dos dados foi baseada no modelo de Signos, Significados e Ações. A maioria dos idosos negou a presença de qualquer transtorno mental, mas identificou signos de sofrimento mental, articulados em três categorias: nervoso, problema de cabeça e doidura. Todos referiram a sintoma que justificaria tratamento e destacaram como causas de transtornos mentais, problemas familiares e vivenciais, físicos, de alimenta- ção e sono, fraqueza moral e debilidade atribuída ao envelhecimento. Apesar de a procura do atendimento ser atribuída à iniciativa de outrem, o tratamento é bem aceito e avaliado, mesmo com certas ressalvas articuladas aos seus próprios conceitos sobre causas e conseqüências de tais perturbações. Os medicamentos foram apontados como principal medida de tratamento, apesar dos efeitos adversos, da baixa eficácia e do modo como são preconizados pelos profissionais de saúde.

Idoso; Saúde Mental; Transtornos Mentais 


\section{Colaboradores}

A. S. Clemente participou do delineamento do estudo, realizou e transcreveu as entrevistas, desenvolveu a análise dos dados e foi o redator principal do artigo. A. I. Loyola Filho participou da discussão do delineamento do estudo e da revisão crítica do trabalho. J. O. A. Firmo orientou o delineamento do estudo, a análise dos resultados e a discussão e a revisão crítica final do artigo.

\section{Agradecimentos}

Agradecemos à diretoria e à comunidade do Hospital Galba Velloso, Fundação Hospitalar do Estado de Minas Gerais, onde o estudo foi realizado, em especial ao Núcleo de Ensino e Pesquisa e ao Serviço de Gestão de Informação. À Dra. Elizabeth Uchôa, pelas sugestões preciosas que floresceram do seu esforço em colaborar com este trabalho.

\section{Referências}

1. Carvalho JAM, Garcia RA. O envelhecimento da população brasileira: um enfoque demográfico. Cad Saúde Pública 2003; 19:725-33.

2. Veras R. Em busca de uma assistência adequada à saúde do idoso: revisão da literatura e aplicação de um instrumento de detecção precoce e de previsibilidade de agravos. Cad Saúde Pública 2003;19:705-15

3. Wong LLR, Carvalho JA. O rápido processo de envelhecimento populacional do Brasil: sérios desafios para as políticas públicas. Rev Bras Estud Popul 2006; 23:5-26

4. Maragno L, Goldbaum M, Gianini RJ, Novaes HMD, César CLG. Prevalência de transtornos mentais comuns em populações atendidas pelo Programa Saúde da Família (QUALIS) no Município de São Paulo, Brasil. Cad Saúde Pública 2006; 22:1639-48.

5. Coelho Filho JM, Ramos LR. Epidemiologia do envelhecimento no Nordeste do Brasil: resultados de inquérito domiciliar. Rev Saúde Pública 1999; 33:445-53.

6. Ramos LR, Rosa TEC, Oliveira ZM, Medina MCG, Santos FRG. Perfil do idoso em área metropolitana na região Sudeste do Brasil: resultados de inquérito domiciliar. Rev Saúde Pública 1993; 27:87-94.
7. Organização Mundial da Saúde. Classificação de Transtornos Mentais e de Comportamento da CID-10: Descrições Clínicas e Diretrizes Diagnósticas. Porto Alegre: Artes Médicas; 1993.

8. Blay SL, Laks J, Nitrini R, Caramelli P. Epidemiologia dos transtornos mentais em idosos e a utilização dos serviços por esta população. In: Mello MF, Mello AAF, Kohn R, organizadores. Epidemiologia da saúde mental no Brasil. Porto Alegre: Artmed; 2007. p. 143-50.

9. Lima MTR, Silva RS, Ramos LR. Fatores associados à sintomatologia depressiva numa coorte urbana de idosos. J Bras Psiquiatr 2009; 58:1-7.

10. Castro-Costa E, Lima-Costa MFF, Carvalhais S, Firmo JOA, Uchôa E. Factors associated with depressive sypmtoms measured by the 12 -item General Health Questionnaire in community-dwelling older adults (The Bambuí Health Aging Study). Rev Bras Psiquiatr 2008; 30:104-9.

11. Gazalle FK, Lima MS, Tavares BF, Curi P. Sintomas depressivos associados em população idosa no Sul do Brasil. Rev Saúde Pública 2004; 38:365-71.

12. Scazufca M, Cerqueira ATAR, Menezes PR, Prince M, Vallada HP, Miyazaki MCOS, et al. Investigações epidemiológicas sobre demência nos países em desenvolvimento. Rev Saúde Pública 2002; 36:773-8. 
13. Oliveira SFD, Duarte YAO, Lebrão ML, Laurenti R. Demanda referida e auxílio recebido por idosos com declínio cognitivo no município de São Paulo. Saúde Soc 2007; 16:81-9.

14. Almeida OP. Idosos atendidos em serviço de emergência de saúde mental: características demográficas e clínicas. Rev Bras Psiquiatr 1999; 21:12-8.

15. Hanlon P, Walsh D, Whyte BW, Scott SN, Lightbody P, Gilhooly MLM. Hospital use by an ageing cohort: an investigation into the association between biological, behavioural and social risk markers and subsequent hospital utilization. J Public Health Med 1998; 20:467-76.

16. Vicente B, Kohn R, Saldivia S, Rioseco P, Torres S. Patrones de uso de servicios entre adultos con problemas de salud mental, en Chile. Rev Panam Salud Pública 2005; 18:263-70.

17. Lima MS. Epidemiologia e impacto social. Rev Bras Psiquiatr 1999; 21 Suppl 1:Sl1-5.

18. Waxman HM. Community mental health care for the elderly: a look at the obstacles. Public Health Rep 1986; 101:294-300.

19. Bandeira M, Calzavara MGP, Costa CS, Cesari L. Avaliação de serviços de saúde mental: adaptação transcultural de uma medida da percepção dos usuários sobre os resultados do tratamento. J Bras Psiquiatr 2009; 58:107-14.

20. Uchôa E, Vidal JM. Antropologia médica: elementos conceituais e metodológicos para uma abordagem da saúde e da doença. Cad Saúde Pública 1994; 10:497-504.

21. Geertz C. A interpretação das culturas. Rio de Janeiro: LTC Editora; 2008.

22. Eisenberg L. Disease and illness: distinctions between professional and popular ideas of sickness. Cult Med Psychiatry 1977; 1:09-23.

23. Kleinman A. Patients and healers in the context of culture. An exploration of borderland between anthropology and psychiatry. Berkeley/Los Angeles: University of California; 1980.

24. Firmo JOA, Lima-Costa MFL, Uchôa E. Projeto Bambuí: maneiras de pensar e agir de idosos hipertensos. Cad Saúde Pública 2004; 20:1029-40.

25. Deslandes SF, Gomes R. A pesquisa qualitativa nos serviços de saúde: notas teóricas. In: Bosi MLM, Mercado FJ, organizadores. Pesquisa qualitativa nos serviços de saúde. Petrópolis: Editora Vozes; 2004. p. 99-120.

26. Delgado PGG, Schechtman A, Weber R, Amstalden AF, Bonavigo E, Cordeiro F, et al. Reforma psiquiátrica e política de saúde mental no Brasil. In: Mello MF, Mello AAF, Kohn R, organizadores. Epidemiologia da saúde mental no Brasil. Porto Alegre: Artmed; 2007. p. 39-79.

27. Mascarenhas MEB. Hospital Galba Velloso: do hospital à rede, um projeto em construção. Jornal $\mathrm{O}$ Risco 2003; p. 4.

28. Fontanella BJB, Ricas J, Turato ER. Amostragem por saturação em pesquisas qualitativas em saúde: contribuições teóricas. Cad Saúde Pública 2008; 24:17-27.
29. Corin E, Uchôa E, Bibeau G, Koumare B. Articulation et variations de systèmes de signes, de sens et d'action. Psychopatologie Africaine 1992; 24:183-204.

30. Duarte LFD. Da vida nervosa nas classes trabalhadoras urbanas. Rio de Janeiro: Jorge Zahar Editor; 1986.

31. Rozemberg B. O consumo de calmantes e o "problema de nervos" entre lavradores. Rev Saúde Pública 1994; 28:300-8.

32. Oliveira AB, Roazzi A. A representação social da "doença de nervos" entre os gêneros. Psicol Teor Pesqui 2007; 23:91-102.

33. Tsu TMJA, Tofolo V. Concepções etiológicas de pacientes psiquiátricas sobre doença mental. Psicol USP 1990; 1:155-66.

34. Villares CC, Redko CP, Mari JJ. Concepções de doença por familiares de pacientes com diagnóstico de esquizofrenia. Rev Bras Psiquiatr 1999; 21 : 36-47.

35. Carvalhais SMM. Estudo epidemiológico e antropológico sobre sintomas depressivos em idosos vivendo em comunidade: Projeto Bambuí [Dissertação de Mestrado]. Belo Horizonte: Centro de Pesquisa René Rachou, Fundação Oswaldo Cruz; 2005.

36. Foucault M. História da loucura na idade clássica. 8a Ed. São Paulo: Perspectiva; 2008.

37. Coelho MTAD, Almeida Filho N. Concepções populares de normalidade e saúde mental no litoral norte da Bahia, Brasil. Cad Saúde Pública 2005; 21:1726-36.

38. Kleinman A, Eisenberg L, Good B. Culture, illness, and care: clinical lessons from anthropologic and cross-cultural research. Ann Intern Med 1978; 88:251-8.

39. Cheniaux Jr. E. Manual de psicopatologia. Rio de Janeiro: Editora Guanabara Koogan; 2002.

40. Kirmayer LJ, Corin E. Inside knowledge - cultural construction of the insight in psychosis. In: Amador XF, David AS, editors. Insight and psychosis. NewYork: Oxford University Press; 1998. p. 193-220.

41. Yang LH, Kleinman A, Link BG, Phelan JC, Lee S, Good B. Culture and sigma: adding moral experience to stigma theory. Soc Sci Med 2007; 64: 1524-35.

42. Goffman E. Estigma: notas sobre a manipulação da identidade deteriorada. Rio de Janeiro: LTC Editora; 1988.

43. Gibson RC, Abel WD, White S, Hickling FW. Internalizing stigma associated with mental illness: findings from a general population survey in Jamaica. Rev Panam Salud Pública 2008; 23:26-33.

44. Lucchesi M, Malik AM. Feasibility of general hospitals psychiatric units in Brazil. Rev Saúde Pública 2009; 43:1-7.

Recebido em 02/Fev/2010

Versão final reapresentada em 22/Out/2010 Aprovado em 06/Dez/2010 